\title{
Ethnic Variation and Its Association With Malaria Awareness: A Cross-sectional Study in East Nusa Tenggara Province, Indonesia
}

\author{
Robertus Dole Guntur ${ }^{1,2}$, Jonathan Kingsley, ${ }^{1,3}$, Fakir M. Amirul Islam ${ }^{1}$ \\ ${ }^{1}$ Department of Health Science and Biostatistics, School of Health Sciences, Swinburne University of Technology, Hawthorn, Australia; ${ }^{2}$ Department \\ of Mathematics, Faculty of Science and Engineering, University of Nusa Cendana, Kupang, Indonesia; ${ }^{3}$ Centre of Urban Transitions, Swinburne \\ University of Technology, Hawthorn, Australia
}

Objectives: This study investigated associations between ethnicity and malaria awareness in East Nusa Tenggara Province (ENTP), Indonesia.

Methods: A community-based cross-sectional study was conducted upon 1503 adults recruited by multi-stage cluster random sampling. A malaria awareness questionnaire was used to collect data, according to which participants were classified as aware or unaware of malaria. Logistic regression was applied to quantify the strength of associations of factors with malaria awareness.

Results: The participation rate in this study was high (99.5\%). The participants were distributed relatively evenly among the Manggarai, Atoni, and Sumba ethnicities (33.0, 32.3, and 30.2\%, respectively). Malaria awareness was significantly different amongst these groups; it was most common in the Manggarai ethnicity (65.1\%; 95\% confidence interval [Cl], 59.9 to 70.3) and least common in the Sumba ethnicity (35.0\%; $95 \% \mathrm{Cl}, 27.6$ to 42.4). The most prominent factor influencing the malaria awareness in the Sumba and Manggarai ethnicities was education level, whilst it was socioeconomic status (SES) in the Atoni ethnicity. The likelihood of malaria awareness was significantly higher in adults with an education level of diploma or above (adjusted odds ratio [aOR], 21.4; $95 \% \mathrm{Cl}, 3.59$ to 127.7 for Manggarai; aOR, $6.94 ; 95 \% \mathrm{Cl}, 1.81$ to 26.6 for Sumba). Malaria awareness was significantly more common amongst high-SES adults in the Atoni group (aOR, 24.48; $95 \% \mathrm{Cl}, 8.79$ to 68.21 ).

Conclusions: Low education levels and low SES were prominent contributors to lower levels of malaria awareness in rural ENTP. Interventions should focus on improving malaria awareness to these groups to support the Indonesian government's national commitment to achieve a malaria elimination zone by 2030.

Key words: Malaria awareness, Rural population, Ethnic groups, Disparity, Malaria elimination

Received: July 1, 2021 Accepted: November 12, 2021

Corresponding author: Robertus Dole Guntur Department of Health Science and Biostatistics, School of Health Sciences, Swinburne University of Technology, 453-457 Burwood Road, Hawthorn 3122, Australia

E-mail: rguntur@swin.edu.au

This is an Open Access article distributed under the terms of the Creative Commons Attribution Non-Commercial License (https://creativecommons.org/licenses/by$\mathrm{nc} / 4.0 /$ ) which permits unrestricted non-commercial use, distribution, and reproduction in any medium, provided the original work is properly cited.

\section{INTRODUCTION}

Malaria is a major health challenge globally across 87 countries and a leading cause of illness and death in many poor, tropical, and sub-tropical countries $[1,2]$. The World Health Organization estimated that in 2019 the numbers of malaria cases and deaths were 229 million and 409000 respectively [2]. Almost $2.8 \%$ of cases are from Southeast Asia (SEA), countries, of which $11 \%$ are from Indonesia [2]. 
In Indonesia, the Ministry of Health, through the National Malaria Control Program, has implemented various interventions to reduce malaria cases with the national commitment to achieve a malaria-free zone in the country by 2030 [3]. The funding for the malaria program increased by about $2.4 \%$ from US dollar (USD) 21170034.7 in 2016 to USD 21683909.81 in 2018 [3]. However, the number of positive cases of malaria remains high across different provinces of Indonesia, but with substantial variation, as shown by the presence of 216380 cases in Papua, 861 cases in South Sulawesi, and 12 cases in Yogyakarta Special Region province [4]. In total, there were 250644 cases in 2019, of which almost 97\% were in the eastern part of the country, including in East Nusa Tenggara Province (ENTP) [4].

ENTP is a province known as "Flobamorata," comprising 5 major islands: Flores, Sumba, Timor, Alor, and Lembata [5]. The total number of malaria cases reported in 2018 was 17192 cases from these islands, with $70 \%$ of the cases accounted for by Sumba and $10 \%$ by Timor [6]. Although some studies have been conducted on malaria in the ENTP [7-9], most investigations did not document malaria awareness from the human standpoint, despite the potential of malaria awareness to play a significant role in achieving and maintaining malaria elimination [10]. High malaria awareness in a community increases the use of insecticide-treated nets to protect from mosquito bites [11], reduces malaria prevalence, and speeds up malaria elimination [12].

Several studies have been undertaken to investigate malaria awareness globally [13-15]. Most of these studies have focused on women participants $[13,14]$. One population-based study representing rural communities conducted in China in 2016 revealed that malaria awareness was more common in men than in women [15]. In SEA, population-based studies have investigated malaria awareness [16-18], but with highly uneven distributions of men and women amongst the respondents. In India [16] and Bangladesh [17] the majority of respondents were men, whilst in Myanmar [18] most respondents were women. Therefore, the potential factors associated with malaria awareness in rural communities, representing balanced voices of men and women, are relatively undocumented in this region. Furthermore, the burden of malaria is higher in rural areas than in urban areas in SEA [19].

In the context of Indonesia, a country with 145 ethnic groups [20], some studies were conducted at a village level to evaluate associations between malaria awareness and socio-demo- graphic factors $[21,22]$. A population-based study in a rural community in Indonesia reported a low level of malaria awareness [23]; however, the diversity of ethnicities in rural communities and their associations with malaria awareness have not yet been investigated. To date, no studies have explored factors associated with malaria awareness in different ethnic groups in the rural population of Indonesia. The investigation of predictors of malaria awareness in rural communities in Indonesia is critical since the burden of malaria is higher in rural areas than in urban areas in Indonesia [3]. Understanding factors contributing to malaria awareness in these communities will help local authorities to allocate resources to strengthen the most vulnerable groups in the community and to reduce malaria awareness disparities amongst different ethnic groups in the community. Therefore, this research was undertaken to fill this gap with the dual aim of investigating ethnic variation and its association with malaria awareness of rural adults in 3 different ethnic groups to support the national commitment of the Indonesia government to eliminate malaria by 2030 [3].

\section{METHODS}

\section{Study Population and Sampling}

This study was based on data obtained from a cross-sectional study in rural areas of ENTP in Indonesia from October to December 2019. Data collection was conducted in 3 out of 22 districts in ENTP [5]. Firstly, the East Sumba district, where the majority of the population was of the Sumba ethnicity $[5,20]$, was categorised as a high malaria endemic setting (MES) [24]. Secondly, the Belu district, where most of the population was of the Atoni ethnicity $[5,20]$, was classified as a medium MES [24]. Finally, East Manggarai district, where much of the population was of the Manggarai ethnicity $[5,20]$, was categorised as a low MES [24]. These 3 ethnic groups are predominant in the province [20]. Participants were recruited using a multistage cluster random sampling procedure with systematic random sampling at a cluster level 4 with 49 villages from 3 districts of ENTP. In each village, 20 to 40 participants were selected, proportionate to the population size of the village, and participants were selected by applying the systematic random sampling method.

\section{Sample Size Calculation}

The sample consisted of 1503 participants aged 18 years to 90 years from the general population in ENTP. The sample size 
calculation was based on the prevalence of malaria in ENTP (1.99\% in 2018, as estimated by the Indonesia Health Ministry) [25]. The comprehensive calculation for this sample size has been previously presented in a prior publication [26]. Overall, the sample size was sufficiently large to detect a minimum 5\% difference in the proportion of malaria awareness amongst high, moderate, and low MES with a statistical power of at least $90 \%$ and a type I error of $5 \%$.

\section{Outcome Variable}

The outcome variable of the study was participants' malaria awareness, which was evaluated by 10 questions on topics including a basic understanding of malaria, main symptoms, transmission mode, prevention measures, and seeking malaria treatment within 24 hours when suffering from malaria. For each question, the correct answer was assigned a score of 1 , and the incorrect answer was marked as 0 . Therefore, the total score ranged from 0 to 10 . Malaria knowledge was evaluated as follows: a score $\geq 8$ was classified as having excellent, a score of 6 or 7 as good, a score of 1 to 5 as poor, and a score of 0 was classified as indicating a complete lack of malaria knowledge. Participants with excellent and good scores were categorised as having malaria awareness, whilst those with poor and 0 scores were classified as being unaware of malaria [15,27]. Malaria awareness was calculated for each ethnicity independently.

\section{Socio-demographic and Environmental Factors by Ethnic Groups}

Ethnicity was classified as Sumba, Atoni, Manggarai, and other ethnicities. The category of other ethnicities encompassed many tribes, including the Sabu, Maumere, Nagakeo, Javaness, Bima, and Bugis. Their number was not significant in this study; therefore, they were classified into a single group of "other" ethnicities. In each ethnic group, demographic information comprising gender, age, education level, main occupation, family size, household income, and socioeconomic status (SES) was collected. Gender was categorised as men or women. Age was classified as 5 groups: $<30$ years old, 30-39 years, 4049 years, 50-59 years, and above 60 years of age. The level of education was categorised as no education, primary education (grades 1 to 6), junior high school (grades 7 to 9), senior high school (grades 10 to 12), and diploma or above [25]. Participants were classified by their occupation as farmers, housewives, entrepreneurs, government or non-government workers, and others [25]. SES was assessed according to the owner- ship of durable assets and housing characteristics, and was categorised as low, moderate, and high SES. The nearest health facilities were classified as village maternity posts, village health posts, public health centres (PHCs), and subsidiary PHCs [28]. The distance to the nearest health facilities was categorised as $<1 \mathrm{~km}, 1-2 \mathrm{~km}, 2-3 \mathrm{~km}$, and $\geq 3 \mathrm{~km}$.

\section{Statistical Analysis}

The participants' socio-demographic and environmental characteristics (including gender, age group, education level, SES, family size, nearest health facilities, and distance to the nearest health facilities) in each ethnicity were reported using descriptive statistics. The associations of malaria awareness with all covariates were evaluated using the chi-square test. The logistic regression method was applied to investigate the factors associated with malaria awareness among adults in rural ENTP. Three models of odds ratio (ORs) with $95 \%$ confidence interval (Cls) were developed: crude ORs ( $95 \% \mathrm{Cls}$ ), age-adjusted and gender-adjusted ORs ( $95 \% \mathrm{Cls}$ ), and adjusted ORs (aORs, with $95 \% \mathrm{Cls}$ ) in a full multiple logistic regression model. A $p$-value of 0.05 or less was deemed to indicate statistical significance. All analyses were conducted using the SPSS version 27 (IBM Corp., Armonk, NY, USA).

\section{Ethics Statement}

This research was approved by the Human Ethics Committee of the Swinburne University of Technology Australia (reference No. 20191428-1490) and the Indonesian Ministry of Health (reference letter: LB.02.01/2/KE.418/2019).

\section{RESULTS}

\section{Socio-demographic Characteristics of Study Participants by Ethnic Groups}

Of the total participants, 8 were excluded because of insufficient information. Of the remaining 1495 participants, approximately equal numbers of participants were from the Manggarai (33.0\%), Atoni (32.3\%), and Sumba (30.2\%) ethnicities. Only $4.5 \%$ of participants were from other ethnicities. The composition of participants was significantly different demographically for each ethnicity except for gender. The proportion of rural adults having no education in the Manggarai ethnicity was the lowest (2.6\%) of all ethnicities, whilst it was the highest in the Sumba ethnicity (36.1\%). Most participants of the Sumba and Manggarai ethnicities (72.1 and 65.9\% respectively) were 


\section{Journal of}

Table 1. Socio-demographic characteristics of study participants in East Nusa Tenggara Province, Indonesia

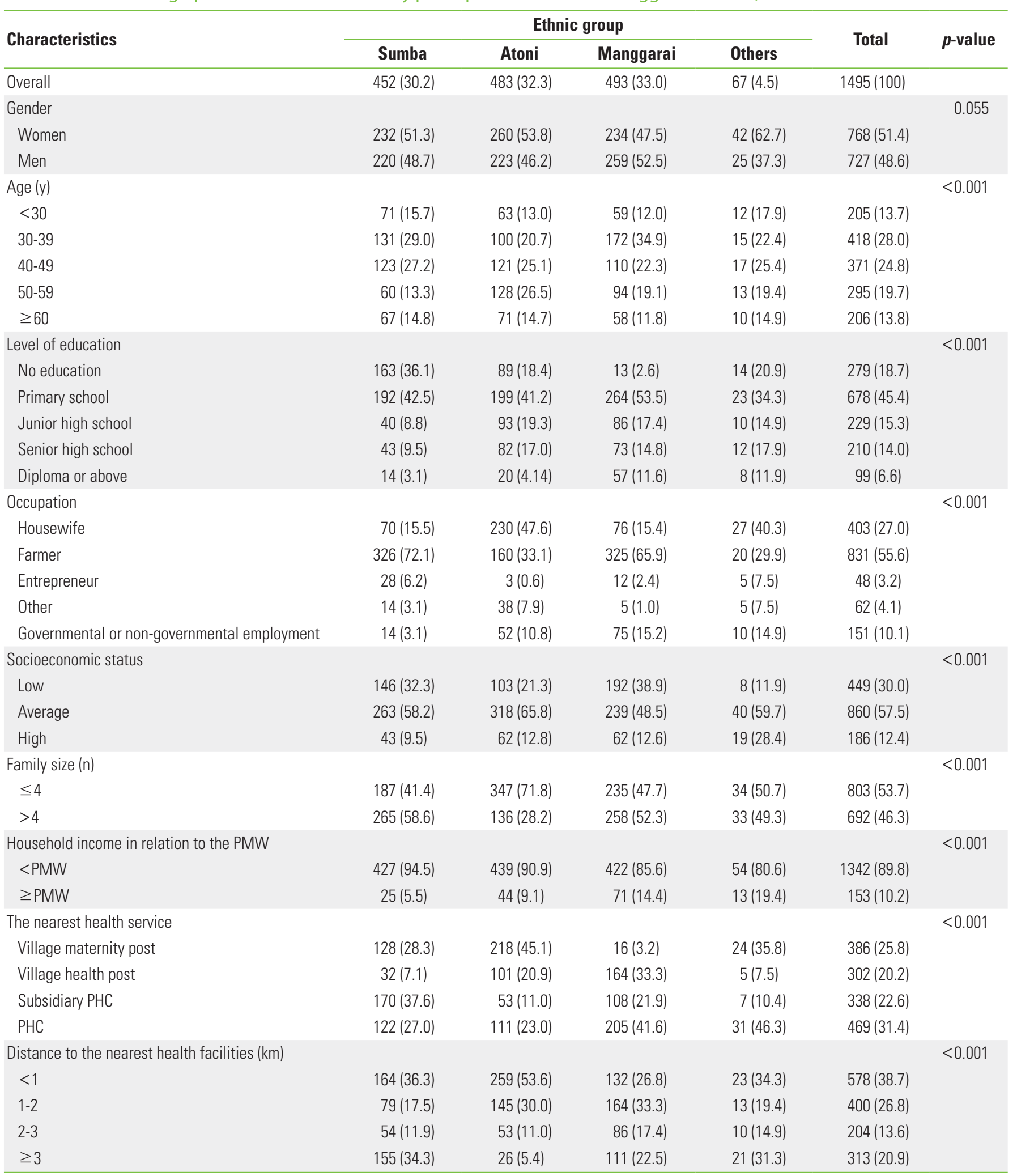

Values are presented as number (\%).

PMW, provincial minimum wage (in 2019: Indonesian rupiah 1795000 monthly); PHC, public health centre. 
farmers, while the most common occupation in the Atoni ethnicity was housewives (47.6\%). The majority of participants in each ethnicity had moderate SES, as shown in Table 1.

\section{Awareness of Malaria by Ethnic Groups}

Malaria awareness by ethnicity is presented in Table 2. Overall, the malaria awareness significantly differed among ethnicities $(p<0.001)$. The highest proportion of individuals with malaria awareness was in the Manggarai ethnicity, accounting for $65.1 \%(95 \% \mathrm{Cl}, 59.9$ to 70.3$)$, whilst it was the lowest in the
Sumba ethnicity (35.0\%; 95\% Cl, 27.6 to 42.4). The level of malaria awareness in the Atoni and other ethnicities was also poor (43.7\%; $95 \% \mathrm{Cl}, 37.0$ to 50.4 and $59.7 \% ; 95 \% \mathrm{Cl}, 44.5$ to $74.9 \%$, respectively).

\section{Awareness of Malaria by Socio-demographic Characteristics and Environmental Characteristics in Each Ethnicity}

Malaria awareness by socio-demographic factors and environmental factors for each ethnicity is presented in Table 3.

Table 2. Distribution of malaria knowledge of rural adults in different ethnicities in East Nusa Tenggara Province, Indonesia

\begin{tabular}{|c|c|c|c|c|c|}
\hline \multirow{2}{*}{ Questions } & \multicolumn{4}{|c|}{ Ethnic group } & \multirow{2}{*}{$p$-value } \\
\hline & Sumba & Atoni & Manggarai & Others & \\
\hline Having heard the term 'malaria' & $439(97.1)[95.5,98.7]$ & $381(78.9)[74.8,83.0]$ & $404(81.9)[78.1,85.7]$ & $63(94.0)[88.1,99.9]$ & $<0.001$ \\
\hline Malaria has dangerous effects on health & $328(72.6)[67.8,77.4]$ & $217(44.9)[38.3,51.5]$ & $363(73.6)[69.1,78.1]$ & $51(76.1)[64.4,87.8]$ & $<0.001$ \\
\hline Malaria can be prevented & $425(94.0)[91.7,96.3]$ & 347 (71.8) [67.1, 76.5] & $384(77.9)[73.7,82.1]$ & $60(89.6)[81.9,97.3]$ & $<0.001$ \\
\hline Main symptoms of malaria & $71(15.7)[7.24,24.2]$ & $220(45.5)[38.9,52.1]$ & $248(50.3)[44.1,56.5]$ & $28(41.8)[23.5,60.1]$ & $<0.001$ \\
\hline Transmission mode of malaria & $295(65.3)[59.9,70.7]$ & $281(58.2)[52.4,64.0]$ & $265(53.8)[47.8,59.8]$ & 42 (62.7) [48.1, 77.3] & 0.004 \\
\hline Sleeping under non-LLINs & $22(4.9)[0.00,13.9]$ & $51(10.6)[2.15,19.0]$ & $267(54.2)[48.2,60.2]$ & $9(13.4)[0.00,35.7]$ & $<0.001$ \\
\hline Sleeping under LLINs & $321(71.0)[66.0,76.0]$ & $199(41.2)[34.4,48.0]$ & $181(36.7)[29.7,43.7]$ & $51(76.1)[64.4,87.8]$ & $<0.001$ \\
\hline Using mosquito coils & $104(23.0)[14.9,31.1]$ & $114(23.6)[15.8,31.4]$ & 108 (21.9) [14.1, 29.7] & $18(26.9)[6.41,47.4]$ & 0.802 \\
\hline Keeping the house clean & $111(24.6)[16.6,32.6]$ & $131(27.1)[19.5,34.7]$ & $275(55.8)[49.9,61.7]$ & $22(32.8)[13.2,52.4]$ & $<0.001$ \\
\hline Seeking treatment for malaria ${ }^{1}$ & $145(32.1)[24.5,39.7]$ & $218(45.1)[38.5,51.7]$ & $289(58.6)[52.9,64.3]$ & $35(52.2)[35.7,68.7]$ & $<0.001$ \\
\hline Malaria awareness & $158(35.0)[27.6,42.4]$ & $211(43.7)[37.0,50.4]$ & $321(65.1)[59.9,70.3]$ & $40(59.7)[44.5,74.9]$ & $<0.001$ \\
\hline
\end{tabular}

Values are presented as number (\%) and [95\% confidence interval].

LLIN, long-lasting insecticide-treated net.

'Seeking treatment within 24 hours when participants or their family members suffered from malaria symptoms.

Table 3. Variations in malaria awareness by socio-demographic and environmental factors of rural adults in East Nusa Tenggara Province, Indonesia

\begin{tabular}{|c|c|c|c|c|c|c|c|c|}
\hline \multirow{3}{*}{ Characteristics } & \multicolumn{8}{|c|}{ Ethnic group } \\
\hline & \multicolumn{2}{|c|}{ Sumba } & \multicolumn{2}{|c|}{ Atoni } & \multicolumn{2}{|c|}{ Manggarai } & \multicolumn{2}{|c|}{ Others } \\
\hline & $\begin{array}{l}\text { No. at } \\
\text { risk }\end{array}$ & $\begin{array}{c}\text { Malaria } \\
\text { awareness }\end{array}$ & $\begin{array}{c}\text { No. at } \\
\text { risk }\end{array}$ & $\begin{array}{c}\text { Malaria } \\
\text { awareness }\end{array}$ & $\begin{array}{l}\text { No. at } \\
\text { risk }\end{array}$ & $\begin{array}{c}\text { Malaria } \\
\text { awareness }\end{array}$ & $\begin{array}{l}\text { No. at } \\
\text { risk }\end{array}$ & $\begin{array}{c}\text { Malaria } \\
\text { awareness }\end{array}$ \\
\hline Total & 452 & $158(35.0)$ & 483 & $211(43.7)$ & 493 & $321(65.1)$ & 67 & $40(59.7)$ \\
\hline \multicolumn{9}{|l|}{ Gender } \\
\hline Women & 232 & $71(30.6)$ & 260 & 93 (35.8) & 234 & $152(65.0)$ & 42 & $26(61.9)$ \\
\hline Men & 220 & 87 (39.5) & 223 & 118 (52.9) & 259 & $169(65.3)$ & 25 & $14(56.0)$ \\
\hline$p$-value & & 0.046 & & $<0.001$ & & 0.946 & & 0.634 \\
\hline \multicolumn{9}{|l|}{ Age (y) } \\
\hline$<30$ & 71 & $23(32.4)$ & 63 & 31 (49.2) & 59 & 33 (55.9) & 12 & $5(41.7)$ \\
\hline $30-39$ & 131 & $48(36.6)$ & 100 & $56(56.0)$ & 172 & $120(69.8)$ & 15 & $11(73.3)$ \\
\hline $40-49$ & 123 & $50(40.7)$ & 121 & 53 (43.8) & 110 & 83 (75.5) & 17 & $12(70.6)$ \\
\hline $50-59$ & 60 & $22(36.7)$ & 128 & 42 (32.8) & 94 & $57(60.6)$ & 13 & $7(53.8)$ \\
\hline$\geq 60$ & 67 & $15(22.4)$ & 71 & $29(40.8)$ & 58 & 28 (48.3) & 10 & $5(50.0)$ \\
\hline$p$-value & & 0.144 & & 0.01 & & 0.002 & & 0.380 \\
\hline
\end{tabular}


Table 3. Continued from the previous page

\begin{tabular}{|c|c|c|c|c|c|c|c|c|}
\hline \multirow{3}{*}{ Characteristics } & \multicolumn{8}{|c|}{ Ethnic group } \\
\hline & \multicolumn{2}{|c|}{ Sumba } & \multicolumn{2}{|c|}{ Atoni } & \multicolumn{2}{|c|}{ Manggarai } & \multicolumn{2}{|c|}{ Others } \\
\hline & $\begin{array}{l}\text { No. at } \\
\text { risk }\end{array}$ & $\begin{array}{c}\text { Malaria } \\
\text { awareness }\end{array}$ & $\begin{array}{l}\text { No. at } \\
\text { risk }\end{array}$ & $\begin{array}{c}\text { Malaria } \\
\text { awareness }\end{array}$ & $\begin{array}{l}\text { No. at } \\
\text { risk }\end{array}$ & $\begin{array}{c}\text { Malaria } \\
\text { awareness }\end{array}$ & $\begin{array}{l}\text { No. at } \\
\text { risk }\end{array}$ & $\begin{array}{c}\text { Malaria } \\
\text { awareness }\end{array}$ \\
\hline \multicolumn{9}{|l|}{ Level of education } \\
\hline No education & 163 & $36(22.1)$ & 89 & $34(38.2)$ & 13 & $5(38.5)$ & 14 & $6(42.9)$ \\
\hline Senior high school & 43 & $26(60.5)$ & 82 & 49 (59.8) & 73 & $51(69.9)$ & 12 & $8(66.7)$ \\
\hline Diploma or above & 14 & $10(71.4)$ & 20 & $16(80.0)$ & 57 & $46(80.7)$ & 8 & $8(100)$ \\
\hline$p$-value & & $<0.001$ & & $<0.001$ & & 0.002 & & 0.059 \\
\hline \multicolumn{9}{|l|}{ Occupation } \\
\hline Governmental or non-governmental employment & 14 & $8(57.1)$ & 52 & $39(75.0)$ & 75 & $55(73.3)$ & 10 & $9(90.0)$ \\
\hline$p$-value & & 0.214 & & $<0.001$ & & 0.052 & & 0.230 \\
\hline \multicolumn{9}{|l|}{ Socioeconomic status } \\
\hline Poor & 146 & $35(24.0)$ & 103 & $13(12.6)$ & 192 & $132(68.8)$ & 8 & $3(37.5)$ \\
\hline Average & 263 & $100(38.0)$ & 318 & $149(46.9)$ & 239 & $151(63.2)$ & 40 & $21(52.5)$ \\
\hline Rich & 43 & $23(53.5)$ & 62 & $49(79.0)$ & 62 & $38(61.3)$ & 19 & $16(84.2)$ \\
\hline$p$-value & & $<0.001$ & & $<0.001$ & & 0.385 & & 0.027 \\
\hline \multicolumn{9}{|l|}{ Household income in relation to the PMW } \\
\hline$<$ PMW & 427 & $140(32.8)$ & 439 & $185(42.1)$ & 422 & $264(62.6)$ & 54 & $28(51.9)$ \\
\hline \multicolumn{9}{|l|}{ Distance to the nearest health facilities (km) } \\
\hline$<1$ & 164 & $55(33.5)$ & 259 & $87(33.6)$ & 132 & $104(78.8)$ & 23 & $15(65.2)$ \\
\hline $1-2$ & 79 & $24(30.4)$ & 145 & $86(59.3)$ & 163 & $108(65.9)$ & 13 & $7(53.8)$ \\
\hline $2-3$ & 54 & $20(37.0)$ & 53 & $30(56.6)$ & 87 & $56(65.1)$ & 10 & $6(60.0)$ \\
\hline$\geq 3$ & 155 & $59(38.1)$ & 26 & $8(30.8)$ & 111 & $53(47.7)$ & 21 & $12(57.1)$ \\
\hline$p$-value & & 0.652 & & $<0.001$ & & $<0.001$ & & 0.911 \\
\hline \multicolumn{9}{|l|}{ The nearest health service } \\
\hline Village health post & 32 & $4(12.5)$ & 101 & $21(20.8)$ & 164 & $103(62.8)$ & 5 & $4(80.0)$ \\
\hline Village maternity post & 128 & $57(44.5)$ & 218 & 89 (40.8) & 16 & $10(62.5)$ & 24 & $13(54.2)$ \\
\hline Subsidiary PHC & 170 & $43(25.3)$ & 53 & $29(54.7)$ & 108 & $71(65.7)$ & 7 & $4(57.1)$ \\
\hline PHC & 122 & $54(44.3)$ & 111 & $72(64.9)$ & 205 & $137(66.8)$ & 31 & $19(61.3)$ \\
\hline$p$-value & & $<0.001$ & & $<0.001$ & & 0.869 & & 0.750 \\
\hline
\end{tabular}

Values are presented as number or number (\%).

PMW, provincial minimum wage (in 2019: Indonesian rupiah 1795000 monthly); PHC, public health centre. 
Significant differences in malaria awareness according to gender were found in the Atoni $(p<0.001)$ and Sumba $(p=0.046)$ ethnicities. In all ethnicities, except in the category of others, the level of malaria awareness was significantly different amongst participants with different education levels, and there was a trend for malaria awareness to become more common

Table 4. Multivariate binary logistic regression': factors associated with malaria awareness among rural adults in East Nusa Tenggara Province, Indonesia

\begin{tabular}{|c|c|c|c|}
\hline \multirow{2}{*}{ Variables } & \multicolumn{3}{|c|}{ Ethnic groups } \\
\hline & Sumba & Atoni & Manggarai \\
\hline \multicolumn{4}{|l|}{ Gender } \\
\hline Women & 1.00 (reference) & 1.00 (reference) & 1.00 (reference) \\
\hline Men & $1.16(0.74,1.79)$ & $1.62(0.65,4.00)$ & $0.76(0.47,1.25)$ \\
\hline \multicolumn{4}{|l|}{ Age (y) } \\
\hline$<30$ & $1.01(0.41,2.47)$ & $0.46(0.17,1.20)$ & $1.26(0.54,2.93)$ \\
\hline $30-39$ & $1.80(0.85,3.81)$ & $0.58(0.25,1.39)$ & $2.40(1.21,4.79)$ \\
\hline $40-49$ & $2.12(1.01,4.46)$ & $0.58(0.26,1.27)$ & $3.33(1.59,6.97)$ \\
\hline $50-59$ & $1.84(0.79,4.25)$ & $0.49(0.23,1.04)$ & $1.49(0.73,3.04)$ \\
\hline$\geq 60$ & 1.00 (reference) & 1.00 (reference) & 1.00 (reference) \\
\hline \multicolumn{4}{|l|}{ Level of education } \\
\hline No education & 1.00 (reference) & 1.00 (reference) & 1.00 (reference) \\
\hline Primary school & $1.72(1.03,2.86)$ & $0.60(0.32,1.13)$ & $2.86(0.83,9.85)$ \\
\hline Secondary school & $3.79(1.95,7.39)$ & $1.88(0.91,3.87)$ & $5.40(1.47,19.9)$ \\
\hline Diploma or above & $6.94(1.81,26.6)$ & $2.99(0.58,15.31)$ & $21.4(3.59,127.7)$ \\
\hline \multicolumn{4}{|l|}{ Occupation } \\
\hline Housewife & - & 1.00 (reference) & 1.00 (reference) \\
\hline Farmer & - & $0.70(0.27,1.83)$ & $2.59(1.37,4.89)$ \\
\hline Entrepreneur & - & $1.45(0.07,31.3)$ & $0.37(0.09,1.48)$ \\
\hline Other & - & $1.87(0.54,6.43)$ & $0.62(0.09,4.47)$ \\
\hline Governmental or non-governmental employment & - & $1.43(0.46,4.48)$ & $0.50(0.14,1.75)$ \\
\hline \multicolumn{4}{|l|}{ Socioeconomic status } \\
\hline Poor & 1.00 (reference) & 1.00 (reference) & - \\
\hline Average & $1.23(0.75,2.03)$ & $5.70(2.75,11.8)$ & - \\
\hline Rich & $1.39(0.61,3.16)$ & $24.48(8.79,68.21)$ & - \\
\hline \multicolumn{4}{|l|}{ Household income in relation to the PMW } \\
\hline$<$ PMW & 1.00 (reference) & 1.00 (reference) & 1.00 (reference) \\
\hline$\geq$ PMW & $2.86(1.05,7.80)$ & $0.37(0.12,1.12)$ & $2.24(0.98,5.15)$ \\
\hline \multicolumn{4}{|l|}{ Distance to the nearest health facilities $(\mathrm{km})$} \\
\hline$<1$ & - & $0.78(0.26,2.32)$ & $4.18(2.28,7.68)$ \\
\hline $1-2$ & - & $1.57(0.51,4.82)$ & $2.84(1.64,4.92)$ \\
\hline $2-3$ & - & $1.79(0.51,6.24)$ & $2.46(1.30,4.65)$ \\
\hline$\geq 3$ & - & 1.00 (reference) & 1.00 (reference) \\
\hline \multicolumn{4}{|l|}{ The nearest health service } \\
\hline Village health post & 1.00 (reference) & 1.00 (reference) & - \\
\hline Village maternity post & $4.95(1.54,15.9)$ & $2.41(1.25,4.64)$ & - \\
\hline Subsidiary PHC & $2.18(0.69,6.90)$ & $6.70(2.66,16.9)$ & - \\
\hline PHC & $4.72(1.46,15.2)$ & $3.58(1.64,7.82)$ & - \\
\hline
\end{tabular}

Values are presented as adjusted odds ratio (95\% confidence interval).

PMW, provincial minimum wage (in 2019: Indonesian rupiah 1795000 monthly); PHC, public health centre.

${ }^{1}$ Adjusted odds ratios for all variables in the model. 
as the level of education was higher. In terms of the main occupation, housewives showed the lowest level of malaria awareness in both the Sumba and Atoni ethnicities (32.9 and $34.3 \%$ respectively). Malaria awareness was significantly different according to SES, particularly in the Sumba and Atoni ethnicities, and the level of malaria awareness increased as SES became higher.

\section{Factors Associated With Malaria Awareness}

After adjustment for all covariates, the following factors were associated with a low level of malaria awareness in the Sumba ethnicity of ENTP: a diploma or above education level compared to those with no education (aOR, 6.94; $95 \% \mathrm{Cl}, 1.81$ to 26.60); living closest to a village maternity post compared to those living closest to a village health post (aOR, 4.95; 95\% $\mathrm{Cl}, 1.54$ to 15.9). In the Atoni ethnicity, the likelihood of malaria awareness among rural adults with high SES was 24 times higher than those with low SES (aOR, 24.48; 95\% Cl, 8.79 to 68.21) and almost 7 times higher amongst those living closest to a subsidiary PHC than those living closest to a village health post (aOR, $6.70 ; 95 \% \mathrm{Cl}, 2.66$ to 16.9). Finally, in the Manggarai ethnicity, the following factors were associated with a higher likelihood of malaria awareness: diploma or above education level compared to no education (aOR, 21.4; $95 \% \mathrm{Cl}, 3.59$ to 127.70), living less than $1 \mathrm{~km}$ from the nearest health facilities compared to living more than $3 \mathrm{~km}$ from the closest health facilities (aOR, 4.18; 95\% Cl, 2.28 to 7.68), and working as a farmer compared to being a housewife $(\mathrm{aOR}, 2.59 ; 95 \% \mathrm{Cl}, 1.37$ to 4.89).

\section{DISCUSSION}

To our knowledge this is the first study focused on the diversity of ethnic groups in relation to malaria awareness in rural adults of Indonesia. The results showed that malaria awareness amongst these 3 groups was significantly different. The highest level of malaria awareness was in Manggarai ethnicity, whilst it was the lowest in the Sumba ethnicity. The most important factor associated with malaria awareness in these rural communities was the education level. This was found particularly in the Sumba and Manggarai ethnic groups. Higher education levels were associated with a higher likelihood of malaria awareness. In contrast, in the Atoni ethnic group, the most prominent factor associated with malaria awareness was SES, although associations were also shown for the distance to the nearest health facilities, the nearest health facilities, and main occupation.

This study demonstrated that there was a significant discrepancy in malaria awareness amongst ethnicities. This result confirmed findings in other countries such as China [15] and Malawi [14] indicating that disparities of malaria awareness existed amongst ethnicities in a community. This study showed that malaria awareness in the Manggarai ethnicity was the highest, whereas it was the lowest in the Sumba ethnicity. The disparity amongst ethnicities revealed variation in terms of the sociodemographic characteristics of those ethnicities [14]. In this study, the huge disparity of malaria awareness amongst ethnicities might be attributed to differences in education levels. In the present study, the proportion of adults with primary or no education in the Sumba ethnicity was higher (79\%) than that in the Manggarai ethnicity (56\%). This situation might contribute to poor health literacy in the community of Sumba ethnicity. Improvements in community health literacy would allow community members to improve their understanding and application of the complexity of various health information on individual and population levels [29].

This study showed that a higher likelihood of malaria awareness accompanied higher levels of education, particularly in the Sumba and Manggarai ethnic groups. This finding confirms the behavioural aspect of malaria studies in other rural settings and other countries such as Malawi [14], India [16], and Bangladesh [17], revealing that education level positively correlated with malaria awareness. This study indicated that in the Manggarai ethnicity, the likelihood of malaria awareness of participants with at least a diploma level of education was 21 times higher than that of participants with no education; in the Sumba ethnicity, the corresponding likelihood was almost 7 times higher. A possible reason for this finding is that people with higher education may have more opportunities to access multiple sources of information [30] and have the capability to understand written information [31], helping them to distinguish various terms related to malaria. However, in the present study, only about $7 \%$ of rural adults in these ethnicities had an education level of a diploma or above. This made them particularly disadvantaged in terms of gaining knowledge of malaria, underscoring the need for more attention from governmental authorities to spread information about malaria education to boost malaria elimination programs in the region. Furthermore, it has been definitively established that higher education is associated with a high awareness of diseases in 
general [32].

In this study, we found that malaria awareness was significantly associated with the distance to the nearest health facilities, particularly in the Manggarai ethnicity. A higher likelihood of malaria awareness in this ethnicity was associated with a shorter distance to the nearest health facilities. This finding is consistent with studies in rural communities in China [15] and Malawi [33]. A reason for this finding may be that health promotion education does not function properly in this province due to the shortage of health workers in PHCs. The basic database of PHCs in ENTP revealed that the distribution of health workers in 381 PHCs was uneven, ranging from 0 to 183 staff in each PHC, and $33 \%$ of all PHCs were not supported by an available general practitioner (GP) [34]. The total number of GPs in the province is 861 (corresponding to 1 GP for 6000 people), reflecting a low level of human resources to provide malaria treatment [6].

Our study further showed that a gender-based disparity in malaria awareness was evident, particularly in the Sumba and Atoni ethnicities. Malaria awareness was higher in men than in women. This finding is consistent with studies on malaria awareness in rural communities in China [15] and Bangladesh [17]. Furthermore, this study also showed that the level of malaria awareness of housewives was lower than that of all other occupations. The low level of malaria awareness among women in ENTP was unexpected by the authors because the Indonesia government has provided informative systems allowing women to improve their malaria knowledge. For instance, the distribution of long-lasting insecticide-treated nets was integrated with immunisation and vitamin A distribution activities at community health centres [35]. All those activities have been run mainly by women, and the participants on those activities have been mostly women. Improving malaria awareness for women in the region is critical considering that they are role models for raising malaria awareness at home [36].

The findings of this study indicate that adults with low SES and low income had low levels of malaria awareness. This is in line with studies conducted in Malawi [14] and Bangladesh [17]. This association might be due to the fact that adults with low SES struggled to access health facilities, leading to poor health information [37].

Community participation is a significant component of progress towards malaria elimination [38]. To encourage active community participation, community members must have a high level of awareness of the disease. This study demonstrated low levels of malaria awareness in rural communities, regardless of gender and age group. Improving malaria awareness of this community is critical for progress in malaria elimination. Promoting equal access to malaria education programs will reduce the gap in malaria awareness levels amongst the group. Finally, our study showed that the Sumba ethnicity, possibly due to their low level of education, was the most vulnerable group, implying that they should be prioritised to improve malaria awareness. Given the low level of education, meaning that many people are unable to read written posters or pamphlets, and the high rate of children dropping out of school in the rural population of this province [39], malaria education communication by loudspeaker announcements might be suitable for this rural community, as has been demonstrated in other countries [40].

The present study applied a large sample size that included adults aged 18 years to 89 years from 3 minority ethnic groups of Indonesia, along with a comparative presentation of data, allowing a comprehensive understanding of malaria awareness in rural communities. However, there are some limitations of the study that should be noted; for instance, the data were collected over a single period, meaning that it was not possible for the authors to follow-up with the participants to assess changes in their perceptions. Data were also captured from minority ethnic groups of only 1 province; therefore, the findings do not fully represent the diversity of minority ethnic groups of Indonesia. The study needs to be duplicated with random samples in other parts of the country to capture a truly representative sample of minority groups of rural adults in terms of malaria awareness at the national level.

In conclusion, this study showed that malaria awareness was low and disparities of malaria awareness amongst ethnicities were found in rural ENTP. The risk factors associated with a low level of malaria awareness included low levels of education, low SES, being a housewife, and living more than $3 \mathrm{~km}$ from the nearest health facility. Disparities in malaria awareness according to gender, age group, education level, occupation, and distance to the nearest health facility were statistically significant within each ethnicity. Public health programs should focus on improving malaria awareness in these vulnerable groups and promoting equal access through a malaria awareness campaign to reduce disparities in awareness amongst these groups. Interventions to improve malaria awareness will support the government's expectations to achieve a malaria-free zone by 2030 . 


\section{CONFLICT OF INTEREST}

The authors have no conflicts of interest associated with the material presented in this paper.

\section{FUNDING}

This research was supported by the Australia Awards Scholarship and the Faculty of Health, Arts and Design at Swinburne University Technology, Australia.

\section{ACKNOWLEDGEMENTS}

We further would like to express our gratitude to the Health Ministry of Indonesia, the governor of ENTP, the heads of the East Sumba, Belu, and East Manggarai district, 9 heads of subdistricts, and 49 village leaders for allowing this research to be conducted in their region. The funders had no role in the design of the study, data collection, analysis, or interpretation of data, or writing the paper.

\section{AUTHOR CONTRIBUTIONS}

Conceptualization: Guntur RD. Data curation: Guntur RD. Formal analysis: Guntur RD. Funding acquisition: Guntur RD. Methodology: Guntur RD. Project administration: Guntur RD. Writing - original draft: Guntur RD. Writing - review \& editing: Guntur RD, Kingsley J, Islam FMA.

\section{ORCID}

Robertus Dole Guntur

$\begin{array}{ll} & \text { https://orcid.org/0000-0002-1597-3644 } \\ \text { Jonathan Kingsley } & \text { https://orcid.org/0000-0002-8528-7164 }\end{array}$

Fakir M. Amirul Islam https://orcid.org/0000-0003-3897-3302

\section{REFERENCES}

1. Centers for Disease Control and Prevention. Malaria's impact worldwide [cited 2021 Mar 17]. Available from: https://www. cdc.gov/malaria/malaria_worldwide/impact.html.

2. World Health Organization. World malaria report 2020: 20 years of global progress and challenges; 2020 [cited $2021 \mathrm{Mar}$ 17]. Available from: https://www.who.int/publications/i/ item/9789240015791.
3. Asia Pacific Malaria Elimination Network. Indonesia national strategic plan 2020-2024; 2020 [cited 2021 Jan 17]. Available from: https://www.apmen.org/resources/indonesia-nationalstrategic-plan-2020-2024.

4. Indonesia Ministry of Health. The current development situation of malaria control program in Indonesia 2019. Jakarta: Indonesia Ministry of Health; 2020 (Indonesian).

5. Central Bureau of Statistics East Nusa Tenggara Province. Nusa Tenggara Timur Province in figures 2020 [cited 2021 Mar 18]. Available from: https://ntt.bps.go.id/publication/2020/04/27/ 080aa7bde0454f07e7848b49/provinsi-nusa-tenggara-timurdalam-angka-2020.html (Indonesian).

6. Health Department of the ENTP. The East Nusa Tenggara Province (ENTP) health profile in 2018 Indonesia. Kupang: ENTP Health Department; 2019, p. 119-122 (Indonesian).

7. Jontari H, Kusnanto $H$, Supargiyono S., Hamim SA, Satyagraha AW, Novijanti N, et al. Malaria pre-elimination assessment in Eastern Indonesia. Outbreak Surveill Investig Rep 2016;9(1): $1-7$.

8. Yoshikawa H, Tokoro M, Nagamoto T, Arayama S, Asih PB, Rozi $\mathrm{IE}$, et al. Molecular survey of Blastocystis sp. from humans and associated animals in an Indonesian community with poor hygiene. Parasitol Int 2016;65(6 Pt B):780-784.

9. Syafruddin D, Bangs MJ, Sidik D, Elyazar I, Asih PB, Chan K, et al. Impact of a spatial repellent on malaria incidence in two villages in Sumba, Indonesia. Am J Trop Med Hyg 2014;91(6): 1079-1087.

10. Moonen B, Cohen JM, Snow RW, Slutsker L, Drakeley C, Smith $\mathrm{DL}$, et al. Operational strategies to achieve and maintain malaria elimination. Lancet 2010;376(9752):1592-1603.

11. Kanyangarara $M$, Hamapumbu H, Mamini E, Lupiya J, Stevenson JC, Mharakurwa S, et al. Malaria knowledge and bed net use in three transmission settings in southern Africa. Malar J 2018;17(1):41.

12. Saha A, Sarker M, Kabir M, Lu G, Müller O. Knowledge, attitudes, and practices regarding malaria control among the slash and burn cultivators in Rangamati Hill tracts of Bangladesh. Malar J 2019;18(1):216.

13. Iyanda $A E$, Osayomi T, Boakye KA, Lu Y. Regional variation and demographic factors associated with knowledge of malaria risk and prevention strategies among pregnant women in $\mathrm{Ni}$ geria. Women Health 2020;60(4):456-472.

14. Sixpence A, Nkoka O, Chirwa GC, Milanzi EB, Mangani C, Mathanga DP, et al. Levels of knowledge regarding malaria causes, symptoms, and prevention measures among Malawian women of 
reproductive age. Malar J 2020;19(1):225.

15. Tang S, Ji L, Hu T, Bishwajit G, Da Feng, Ming H, et al. Determinants of public malaria awareness during the national malaria elimination programme: a cross-sectional study in rural China. Malar J 2016;15(1):372.

16. Singh MP, Saha KB, Chand SK, Savargaonkar D. Socioeconomic determinants of community knowledge and practice in relation to malaria in high- and low-transmission areas of central India. J Biosoc Sci 2020;52(3):317-329.

17. Ahmed SM, Haque R, Haque U, Hossain A. Knowledge on the transmission, prevention and treatment of malaria among two endemic populations of Bangladesh and their health-seeking behaviour. Malar J 2009;8:173.

18. Naing PA, Maung TM, Tripathy JP, Oo T, Wai KT, Thi A. Awareness of malaria and treatment-seeking behaviour among persons with acute undifferentiated fever in the endemic regions of Myanmar. Trop Med Health 2017;45:31.

19. World Health Organization. Malaria in South-East Asia [cited 2020 Aug 8]. Available from: https://www.who.int/southeastasia/health-topics/malaria.

20. Ananta A, Arifin EN, Hasbullah MS. Demography of Indonesia's ethnicity. Singapore: ISEAS Publishing; 2015, p. 119-122.

21. Simanjorang C, Kodim N, Achmadi UF, Miko TY. Knowledge and compliance with the use of insecticide-treated nets in Manalu Sangihe Islands Regency of North Sulawesi Indonesia. Indian J Public Health Res Dev 2020;11(5):626-629.

22. Rahmasari FV, Setyonugroho W, Swarjana IK, Arisandi D, Kesetyaningsih TW. The association between demographic and attitude factors with the practice of malaria prevention among the rural community in Purworejo district, Indonesia. Qanun Med 2015;5(1):113-124.

23. Guntur RD, Kingsley J, Islam FM. Malaria awareness of adults in high, moderate and low transmission settings: a cross-sectional study in rural East Nusa Tenggara Province, Indonesia. PLoS One 2021;16(11):e0259950.

24. Indonesia Ministry of Health. The current development situation of malaria control program in Indonesia 2018. Jakarta: Indonesia Ministry of Health; 2019 (Indonesian).

25. Indonesia Ministry of Health. National report of basic health research 2018; 2019 [cited 2019 Mar 16]. Available from: https:// www.litbang.kemkes.go.id/laporan-riset-kesehatan-dasar-riskesdas/(Indonesian).

26. Guntur RD, Kingsley J, Islam FM. Epidemiology of malaria in East Nusa Tenggara Province in Indonesia: protocol for a crosssectional study. JMIR Res Protoc 2021;10(4):e23545.
27. Tang S, Ji L, Hu T, Wang R, Fu H, Shao T, et al Public awareness of malaria in the middle stage of national malaria elimination programme. A cross-sectional survey in rural areas of malariaendemic counties, China. Malar J 2016;15(1):373.

28. National Research Council. Reducing maternal and neonatal mortality in Indonesia: saving lives, saving the future. Washington, DC: National Academies Press; 2013, p. 41.

29. Peerson A, Saunders M. Health literacy revisited: what do we mean and why does it matter? Health Promot Int 2009;24(3): 285-296.

30. Blanch-Hartigan D, Viswanath K. Socioeconomic and sociodemographic predictors of cancer-related information sources used by cancer survivors. J Health Commun 2015;20(2):204-210.

31. Berkman ND, Sheridan SL, Donahue KE, Halpern DJ, Crotty K. Low health literacy and health outcomes: an updated systematic review. Ann Intern Med 2011;155(2):97-107.

32. Alsous M, Abdel Jalil M, Odeh M, Al Kurdi R, Alnan M. Public knowledge, attitudes and practices toward diabetes mellitus: a cross-sectional study from Jordan. PLoS One 2019;14(3): e0214479.

33. Larson PS, Mathanga DP, Campbell CH Jr, Wilson ML. Distance to health services influences insecticide-treated net possession and use among six to 59 month-old children in Malawi. Malar J 2012;11:18.

34. Indonesia Ministry of Health. Basic database of public health centre in East Nusa Tenggara Province Indonesia, condition at 31 December 2018; 2019 [cited 2020 May 20]. Available from: https://pusdatin.kemkes.go.id/resources/download/pusdatin/ data-dasar-puskesmas/2019/19.\%20Buku\%20\%20Data\%20 Dasar\%20PKM-NTT.pdf (Indonesian).

35. Indonesia Ministry of Health. Guidelines for implementing the distribution of treated mosquito nets in Eastern Indonesia 2017. Jakarta: Indonesia Ministry of Health; 2017 (Indonesian).

36. Deressa W, Ali A. Malaria-related perceptions and practices of women with children under the age of five years in rural Ethiopia. BMC Public Health 2009;9:259.

37. Syed ST, Gerber BS, Sharp LK. Traveling towards disease: transportation barriers to health care access. J Community Health 2013;38(5):976-993.

38. Whittaker M, Smith C. Reimagining malaria: five reasons to strengthen community engagement in the lead up to malaria elimination. Malar J 2015;14:410.

39. Guntur RD, Lobo M. Statistical modelling for dropped out school children (DOSC) in east Nusa Tenggara Province Indonesia. J Phys Conf Ser 2017;812:012073. 
Journal of

Preventive Medicine

Ethnic Variation \& Malaria Awareness

\& Public Health

40. Aung PL, Pumpaibool T, Soe TN, Burgess J, Menezes LJ, Kyaw

practice among people living in a malaria endemic area of $M P$, et al. Health education through mass media announcenorthern Myanmar. Malar J 2019;18(1):362.

ments by loudspeakers about malaria care: prevention and 